\title{
Wave Mathematical Model to Describe Gas Chromatography
}

\section{B. Kravchenko}

Odesa National Academy of Food Technologies, 112 Kanatna str., Odesa, 65039, Ukraine

E-mail: kravtchenko@i.ua

This paper describes the mathematical model of concentration waves passing through a layer of adsorbent. The analytic solution to this model deduced for eigenwaves of adsorptive layer had been found. It allows finding the analytical decisions for concentration signal of arbitrary waveform passing through adsorbing layer. To do this the concentration signal at the input of the adsorption layer must be decomposed into the set of eigenwaves, and then to obtain the analytical solution for each of these proper concentration waves at the outlet of adsorbed layer. Next, all solutions for their proper concentration waves are combined into a new solution, which is the solution for an arbitrary concentration signal that passes through the adsorbent layer. This approach allows us to find solutions for any periodic adsorption processes and allows to consider the variable component concentrations or variable flow losses at the entrance to the adsorption layer. A wave approach to the analysis of periodic adsorption processes gives an explanation to the empirical Van Deemter equation used in the practice of gas chromatography.

Key words: Adsorption; Wave; Gas Chromatography; Van Deemter Equation

\section{Хвильова математична модель для газової хроматографії}

\author{
М. Б. Кравченко \\ Одеська національна академія харчових технологій, вул. Канатна, 112, Одеса, 65039, Україна \\ E-mail: kravtchenko@i.ua
}

\begin{abstract}
Дана стаття описує математичну модель коничентраційних хвиль, щуо проходять через шар адсорбенту. Для власних хвиль адсорбиійного шару знайдено аналітичне рішення иієї моделі. Це дозволяє знаходити аналітичні рішення для концентраџійного сигналу довільної форми, який проходить через адсорбційний шар. Для иього потрібно концентраційний сигнал на вході адсорбційного шару розкласти в набір власних хвиль, а потім отримати аналітичне рішення для кожної з ичих власних концентраційних хвиль. Далі всі рішення для власних концентраційних хвиль об 'єднуються в нове рімення, яке і є рішенням для довільного концентраційного сигналу, який проходить крізь шар адсорбенту. Такий підхід дозволяє знаходити рішення для будь-яких періодичних процесів адсорбиії та дозволяе враховувати змінну концентрацію компонентів або змінну витрати потоку на вході до адсорбиійного шару. Хвильовий підхід до аналізу періодичних адсорбиійних прочесів дає пояснення емпіричному рівнянню ван Деемтера, щэо використовуються в практиці газової хроматографії.
\end{abstract}

Ключові слова: Адсорбиія; Хвиля; Газова хроматографія; Рівняння Ван Деемтера

C The Author(s) 2017. This article is an open access publication

This work is licensed under the Creative Commons Attribution 4.0 International License (CC BY)

http://creativecommons.org/licenses/by/4.0/

\section{Introduction}

Chromatography is a physical method of separation in which the components to be separated are distributed between two phases, one of which is stationary while the other mobile phase moves in a definite direction [1-3].

The various chromatographic processes named according to the physical state of the mobile phase. Thus, in gas chromatography (GC), the mobile phase is a gas, and in liquid chromatography, the mobile phase is a liquid. A subclassification made according to the state of stationary phase. If stationary phase is a solid, the GC technique called gas-solid chromatography; and if it is a liquid, the technique called gas-liquid chromatography.

This paper discusses only gas-solid chromatography (GSC).

Separations of components put through a gas chromatography process with solid stationary phase based on a different adsorption value of separated substances.

The mobile phase in gas chromatography is an inert 


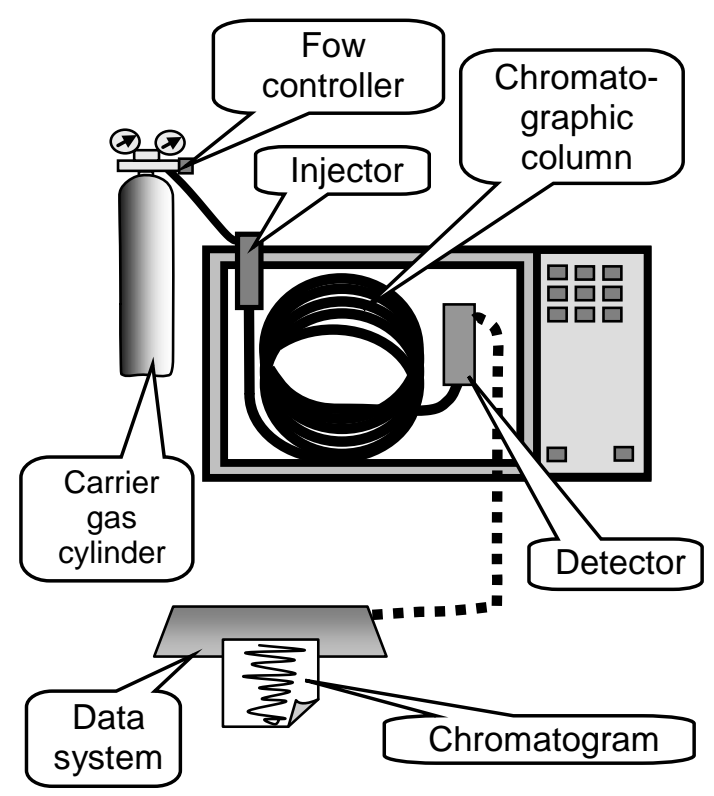

Figure 1 - The schematic diagram of the gas chromatography apparatus.

gas, usually helium, but sometimes nitrogen or argon. This mobile phase often called the carrier gas.

The schematic diagram of a gas chromatography apparatus is shown in Figure 1. The key parts of a gas chromatograph include carrier gas cylinder, flow controller, injector, chromatographic column, detector, and data system.

Chromatographic analysis starts with a quick injection of a test mixture into flow of carrier gas. While being transported through chromatographic column, different components migrate through the column with different velocities by differently interacting with the adsorbent in the column. As a result, each component is retained in the column for different amount of time, known as a retention time. Different retention times cause the components to pass through the column outlet separately from each other.

The initial gas mixture separated into a series of binary mixtures one component of which is a carrier gas, and other component from the analyzed mixture. When this binary mixtures passes through a detector, the latter generates a response indicative change in the properties of the gas mixture. A way to observe separation result is through a chromatogram, which is a plot of the detector response as a function of time elapsed since the injection of a test mixture.

Working gas chromatograph is because the retention time of each component is an individual property of this component, and does not depend on a composition of analysed mixture. Therefore, if the conditions of analysis are constant, whatever a composition of initial mixture, the peak corresponding to the substance will always be in place.

For quantitative analysis of a mixture used height or area of peaks in the obtained chromatogram. The height and area of chromatographic peaks are proportional to concentration of components in a feeding gas mixture.

Despite the fact that gas chromatography is widely used method, and it is rightly considered as one of the most theoretically founded methods, the practice of gas chromatography allows putting a number of questions are difficult to answer in the framework of existing theoretical concepts. The most obvious of these difficult questions: Why the chromatographic separation better achieved at high temperature of absorption column?

It is well known that adsorption of gases increases with decreasing temperature of adsorbent. If gas chromatography based on multiple repetitions of adsorption and desorption of a components of mixture, it would appear reasonable that separation of the mixture would be better at a lower temperature of adsorption column. However, chromatographic separation processes normally executed at elevated temperature, usually about $100-200{ }^{\circ} \mathrm{C}$.

Sometimes higher temperature of the chromatographic column required that all components of the mixture to be in the gaseous state. However, even in a case where the boiling temperature of all components of mixture significantly below room temperature, separating of this mixture still performed at increased temperature [4-6].

On the other hand, it is known that purification of gases by adsorption is always carried out at lower temperature, if it possible.

The incompleteness of modern concepts of gas chromatography illustrated by the example of temperature programmed gas chromatography. The application of

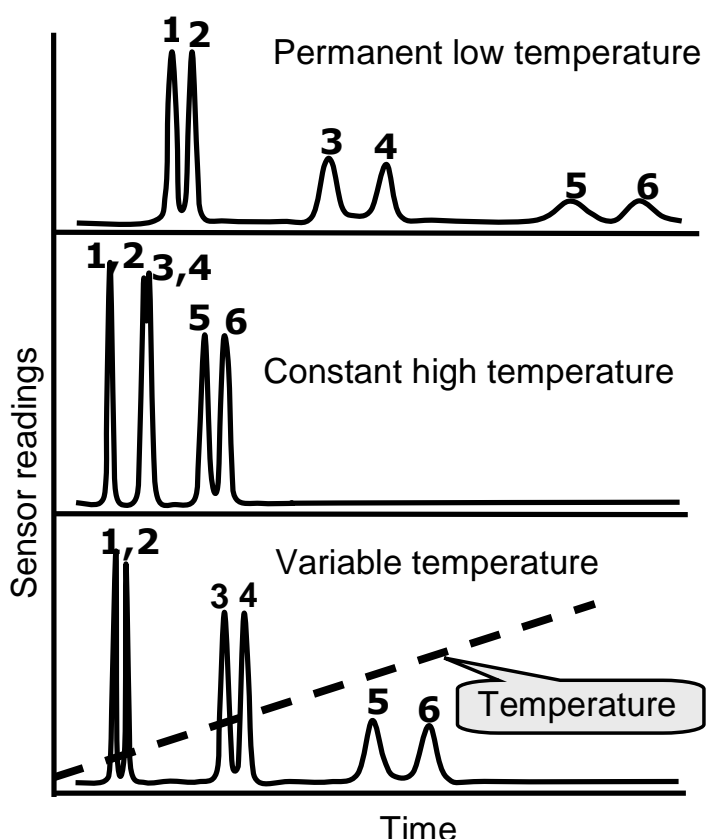

Figure 2 - The typical form of gas chromatograms at a constant and a variable temperature of adsorption column. 
temperature programming is a very adequate way to speed up a gas chromatographic analysis. This technique also used for the analysis of gas mixtures with widely differing properties [6-9].

The Figure 2 shows typical view of chromatograms, which obtained at constant and variable temperatures of adsorption column in chromatographic separation process. It is clearly visible, that peaks in the beginning of the chromatogram completely separated from each other at low temperatures of column, but peaks corresponding to the various components at the end of chromatogram broadened at this temperature. Vice versa, peaks of chromatogram become sharper in the case where the temperature of adsorption column is elevated, but the distance between adjacent peaks decreased.

If in the act of separation gradually increase column temperature from minimum to maximum, the form of chromatogram will be improved in terms of mixtures quantitative and qualitative analysis.

The gas adsorption increases with decreasing temperature. Therefore, increasing distance between concentration peaks at low temperature well explained in the framework of existing ideas about physical mechanisms of gas chromatography.

However, the sharp concentration peaks apparently bound with some other factor, which increases with increasing the temperature. One can assume that this factor is the longitudinal diffusion of a component in a carrier gas, since it increases with increasing the temperature, but the effect of diffusion usually explained the reverse process of broadening concentration peaks at the column outlet.

The effect of this factor on the process of gas chromatography so significant that separation of gas mixtures at their chromatographic analysis practically always carried out at increased temperature, despite the fact that the adsorption in this case significantly reduced.

From this, it follows that our understanding of separation mechanisms in gas chromatography are not comprehensive, and they need to clarify.

\section{Material and Methods}

\subsection{Gas adsorption in porous adsorbent bed}

We now consider the adsorption of a component, which dissolved in the carrier gas.

When constructing the mathematical model of adsorption process we will take the following physical interpretation of the component spreading processes in a microporous adsorbent.

The carrier gas mixed with component, what we are interested, filtered through a porous adsorbent bed. Near the points of tangency of the adsorbent grains are the stagnant zones in which the carrier gas is almost stationary.

The gas flow passes through an array of holes in the empty spaces between the adsorbent grains.

Thus, all space, filled with adsorbent, can be divided into two zones: a stationary frame consisting from grains of adsorbent and adjacent stagnant zones, and the system of holes in which the carrier gas with dissolved component are moving.

The component in stationary frame spread mainly due to its molecular diffusion in the gas, filling the micropores in the adsorbent grains and stagnant zones around them.

The component in the system consisting of randomly arranged holes in stationary frame propagated by convection.

Thus, the diffusible component in the stationary frame and gas stream in the system of holes is moving along paths, which are substantially none intersects (see Figure 3). The interactions between these streams occur along the boundary of the array of holes, in which moves

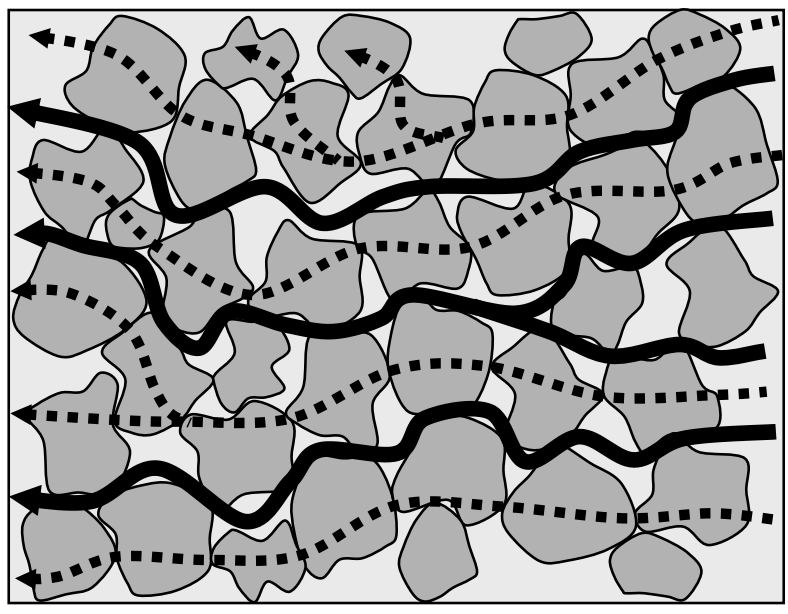

Figure 3 - The ccomponent spreading pattern in adsorbent bed.

4.1. the motion of the diffusing component in a stationary frame;

the carrier gas line of current.

the carrier gas.

This physical pattern of the gas propagation through a porous adsorbent bed is very different from the conventional scheme of mathematical description of the adsorption, which provided, for example, in [10-12].

In the traditional approach considered diffusion of adsorbed component inside the moving carrier gas.

In the proposed formulation of this problem, removing the component from stationary frame to the moving carrier gas seems as a drain of this component in problem of molecular diffusion in the pores of adsorbent.

The convection of this component in the channels with moving carrier gas is described the separated equation. As evidenced by the foregoing, the equation of molecular diffusion in the stationary frame can be writen as:

$$
\begin{aligned}
& D_{E} \frac{\partial^{2} C(x, \tau)}{\partial x^{2}}-\beta \cdot F(C(x, \tau)-C g(x, \tau))= \\
& =K_{G} \frac{\partial C(x, \tau)}{\partial \tau}
\end{aligned}
$$


where $C$ is actual volumetric concentration of the component in the stationary frame (gas in the pores of adsorbent and stagnant areas around the adsorbent particles) $\left[\mathrm{m}^{3} / \mathrm{m}^{3}\right]$;

$\mathrm{Cg}$ is actual volumetric concentration of the component in the moving carrier gas $\left[\mathrm{m}^{3} / \mathrm{m}^{3}\right]$;

$\beta$ is kinetic coefficient of mass transfer between the gas in the stationary frame and the moving carrier gas, $\left[\mathrm{m}^{3} /\left(\mathrm{s} \cdot \mathrm{m}^{2}\right)\right]$

$F$ is specific contact surface of the stationary frame and the moving carrier gas, $\left[\mathrm{m}^{2} / \mathrm{m}^{3}\right]$;

$D_{E}$ is equivalent value of the diffusion coefficient in the stationary frame, is equal to product of the diffusion coefficient in the carrier gas and relative value of the effective pore cross section in the stationary frame, $\left[\mathrm{m}^{2} / \mathrm{s}\right]$.

$K_{G}$ is dimensionless Henry constant for adsorption isotherm.

We notice that diffusion equation, recorded for the stationary frame, included the Henry constant. This means that the proposed mathematical model of gas adsorption is linear model. The isotherm used to modelling adsorption known as Henry's adsorption isotherm.

The material balance of component in elementary volume of carrier gas, moving inside the adsorbent bed, can write in the form of another differential equation:

$$
\beta F(C(x, \tau)-C g(x, \tau))-G \frac{d C g(x, \tau)}{d x}=0 ;
$$

where $G$ is the volumetric flow rate of carrier gas related to a unit section of the adsorbent bed, $\left[\mathrm{m}^{3} / \mathrm{s}\right]$.

These two equations, when it considered together, make it possible to find the distribution of the component concentration in the moving carrier gas and in the stationary frame.

\subsection{Wave Mathematical Model of Adsorption}

We consider the component passage through a bed of adsorbent, having a width $h$.

We assume that the volumetric concentration of the component in the carrier gas in the inlet section of the adsorbent bed varies harmonically, as shown in the Figure 4.

In this paper, we consider the steady adiabatic adsorption process in the thermally insulated adsorbent bed.

If we consider a steady state movement of a concentration wave through the adsorbed layer, according to Prigogine theorem, entropy production in this layer should reach its minimum.

Because the adsorption accompanied by heat effect and heat transfer is basically an irreversible process, the heat that was given in the adsorption process, can never be returned completely in the desorption process.

Therefore, the steady-state process, in which periodically changed mass of the adsorbed substance, by definition, will be essentially irreversible. It follows that the minimum entropy production in the steady-state movement of concentration wave will be achieved if the mass of the adsorbed component remains unchanged. Therefore, in this mathematical model used the convention about the constancy of mass of the component that adsorbed in the adsorbent bed.

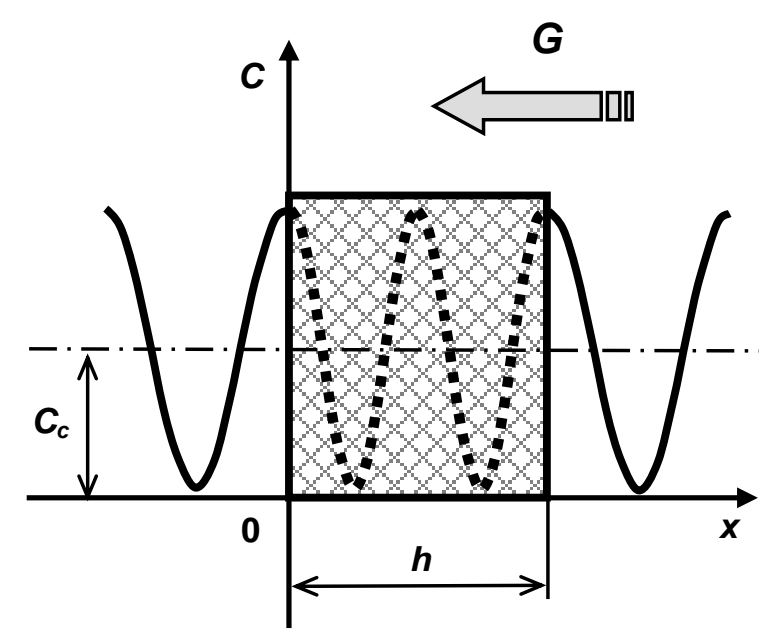

Figure 4 - The concentration eigenwave spreading through the adsorbent bed.

The constancy weight of component is only achieved for the oscillation frequencies, at which the instantaneous values of the component concentration at the inlet of the adsorbent bed is equal to the instantaneous value of its concentration at the outlet of this adsorbent bed. This is possible only when the concentration wavelength in the stationary frame is equal to the thickness of the adsorbent layer.

Following the conventional terminology, we call these oscillations of the concentration - eigenmodes of this adsorbent bed, and frequency of these oscillations eigenfrequencies of the adsorbent bed.

In considered mathematical model is also accepted assumption that the gas, filling the pores of the adsorbent, and the gas adsorbed on its surface are in thermodynamic equilibrium.

For this physical interpretation the spreading of component in the porous adsorbent bed, initial condition for equation (1) can be written as:

$$
C(x, 0)=C o(x) .
$$

Neumann boundary condition:

$$
\frac{\partial C(0, \tau)}{\partial x}=0 ; \quad \frac{\partial C(h, \tau)}{\partial x}=0 .
$$

The physical sense of these boundary conditions is the end surfaces of the adsorbed layer is not absorbed and does not leave the considered component. The mass transfer performed only between a moving carrier gas and the stationary frame of the adsorbent bed. 
We write the equation (1) in the operator form ( $\mathrm{S}-$ operator of differentiation with respect to time) [13]:

$$
\begin{aligned}
& D_{E} \frac{\partial^{2} C(x, s)}{\partial x^{2}}-\beta F(C(x, s)-C g(x, s))= \\
& =s K_{G} C(x, s)-C o(x)
\end{aligned}
$$

The boundary conditions also may be written in the operator form:

$$
\frac{\partial C(0, s)}{\partial x}=0 ; \quad \frac{\partial C(h, s)}{\partial x}=0 .
$$

We construct the finite integral cosine transform to the coordinate $x$ :

$$
\bar{C}_{k}(s)=\int_{0}^{h} C(x, s) \cos \left(\mu_{k} \frac{x}{h}\right) d x, \quad k=0,1,2 \ldots
$$

The inversion formula:

$$
C(x, s)=\sum_{k=0}^{\infty} \frac{\bar{C}_{k}(s)}{\left\|\psi_{k}\right\|^{2}} \cos \left(\mu_{k} \frac{x}{h}\right) .
$$

Where $\left\|\psi_{k}\right\|^{2}$ is the square of the norm of the integral transform kernel:

$$
\left\|\psi_{k}\right\|^{2}=\int_{0}^{h} \cos ^{2}\left(\mu_{k} \frac{x}{h}\right) d x .
$$

The last expression is the tabular integral:

$$
\begin{aligned}
& \left\|\psi_{k}\right\|^{2}=\int_{0}^{h} \cos ^{2}\left(\mu_{k} \frac{x}{h}\right) d x= \\
& =\left.\left(\frac{x}{2}+\frac{h}{2 \mu_{k}} \sin \left(2 \mu_{k} \frac{x}{h}\right)\right)\right|_{0} ^{h}= \\
& =\frac{h}{2}+\frac{h}{2 \mu_{k}} \sin \left(2 \mu_{k}\right)
\end{aligned}
$$

Let convert the image of expression for the second derivative of the component concentration by the formula for integration by parts:

$$
\begin{aligned}
& \int_{0}^{h} \frac{\partial^{2} C(x, s)}{\partial x^{2}} \cos \left(\mu_{k} \frac{x}{h}\right) d x= \\
& =\left.\frac{\partial C(x, s)}{\partial x} \cos \left(\mu_{k} \frac{x}{h}\right)\right|_{0} ^{h}+ \\
& +\frac{\mu_{k}}{h} \int_{0}^{h} \frac{\partial C(x, s)}{\partial x} \sin \left(\mu_{k} \frac{x}{h}\right) d x= \\
& =\left[\left.\begin{array}{l}
\frac{\partial C(x, s)}{\partial x} \cos \left(\mu_{k} \frac{x}{h}\right)+ \\
+C(x, s)\left(\frac{\mu_{k}}{h}\right) \sin \left(\mu_{k} \frac{x}{h}\right)
\end{array}\right|_{0} ^{h}-\right. \\
& -\frac{\mu_{k}^{2}}{h^{2}} \int_{0}^{h} C(x, s) \cos \left(\mu_{k} \frac{x}{h}\right) d x \text {. }
\end{aligned}
$$

Let find eigenvalues $\mu_{\mathrm{k}}$ of the integral transform to ensure compliance with boundary conditions.

The boundary condition at $x=0$ :

$$
\begin{aligned}
& {\left.\left[\frac{\partial C(x, s)}{\partial x} \cos \left(\mu_{k} \frac{x}{h}\right)+C(x, s)\left(\frac{\mu_{k}}{h}\right) \sin \left(\mu_{k} \frac{x}{h}\right)\right]\right|_{x=0}=} \\
& =\frac{\partial C(0, s)}{\partial x}=0 .
\end{aligned}
$$

Therefore, the boundary condition at $x=0$ for a cosine transform is performed automatically.

The boundary condition at $x=h$ :

$$
\begin{aligned}
& {\left[\frac{\partial C(x, s)}{\partial x} \cos \left(\mu_{k} \frac{x}{h}\right)+C(x, s)\left(\frac{\mu_{k}}{h}\right) \sin \left(\mu_{k} \frac{x}{h}\right)\right]^{x=h}=} \\
& =\left[\frac{\partial C(h, s)}{\partial x} \cos \left(\mu_{k}\right)+C(h, s)\left(\frac{\mu_{k}}{h}\right) \sin \left(\mu_{k}\right)\right]
\end{aligned}
$$

Find the eigenvalues of the integral transform such as to satisfy the condition:

$$
\frac{\partial C(h, s)}{\partial x} \cos \left(\mu_{k}\right)+C(h, s)\left(\frac{\mu_{k}}{h}\right) \sin \left(\mu_{k}\right)=0 .
$$

Then dividing right and left sides of this equation to $\cos \left(\mu_{k}\right)$, obtain:

$$
\frac{\partial C(h, s)}{\partial x}=-C(h, s) \cdot\left(\frac{\mu_{k}}{h}\right) \cdot \operatorname{tg}\left(\mu_{k}\right)=0 .
$$

Comparing with the second boundary condition, we obtain the formula for finding the eigenvalues:

$$
\begin{aligned}
& \operatorname{tg}\left(\mu_{k}\right)=0 ; \\
& \mu_{k}=\pi k .
\end{aligned} \quad k=0,1,2 \ldots
$$

Taking this into account, we obtain an expression for the integral transform:

$$
\begin{aligned}
& \int_{0}^{h} \frac{\partial^{2} C(x, s)}{\partial x^{2}} \cos \left(\pi \cdot k \frac{x}{h}\right) d x= \\
& =-\frac{(\pi \cdot k)^{2}}{h^{2}} \int_{0}^{h} C(x, s) \cos \left(\pi \cdot k \frac{x}{h}\right) d x= \\
& =-\frac{(\pi \cdot k)^{2}}{h^{2}} \bar{C}_{k}(s) .
\end{aligned}
$$

After cosine-transform, diffusion equation in the stationary frame (1) takes the form:

$$
\begin{aligned}
& -\frac{(\pi k)^{2}}{h^{2}} \bar{C}_{k}(s)=\left(s \frac{K_{G}}{D_{E}}+\frac{\beta F}{D_{E}}\right) \bar{C}_{k}(s)+ \\
& +\frac{1}{D_{E}} \int_{0}^{h} C o(x) \cdot \cos \left(\pi k \frac{x}{h}\right) d x-\frac{\beta F}{D_{E}} \overline{C g}_{k}(s) ;
\end{aligned}
$$

Hence, we find the image of the function describing the concentration of the component in a stationary frame: 


$$
\begin{aligned}
& -\bar{C}_{k}(s)=\frac{1}{\left(\frac{(\pi k)^{2}}{h^{2}}+s \frac{K_{G}}{D_{E}}+\frac{\beta F}{D_{E}}\right)} \times \\
& \times \int_{0}^{h} C o(x) \cos \left(\pi k \frac{x}{h}\right) d x- \\
& -\frac{\beta F}{\left(\frac{(\pi k)^{2}}{h^{2}}+s K_{G}+\frac{\beta F}{D_{E}}\right)} \overline{C g}_{k}(s) ;
\end{aligned}
$$

For simplicity, we choose zero value of the initial temperature distribution:

$$
\operatorname{Co}(x)=0 \text {. }
$$

With this in mind, we obtain:

$$
\bar{C}_{k}(s)=\frac{\beta F \cdot \overline{C g}_{k}(s)}{\left(\frac{(\pi k)^{2}}{h^{2}}+\frac{s}{D_{E}} K_{G}+\frac{\beta F}{D_{E}}\right)} ;
$$

or

$$
\bar{C}_{k}(s)=\frac{D_{E} \cdot \frac{\beta F}{K_{G}} \cdot \overline{C g}_{k}(s)}{\left(s+\frac{\beta F}{K_{G}}+\frac{(\pi k)^{2} D_{E}}{h^{2} K_{G}}\right)}
$$

For further investigation, we specified wave nature of concentration oscillation in the carrier gas. This means that if we know the period of oscillations, the length of concentration eigenwave can found by knowing the width of the adsorbing layer:

$$
\begin{gathered}
C g_{k}(x, \tau)=A_{k} \cos \left(2 \pi k\left(\frac{x}{h}+\frac{\tau}{T}\right)\right)= \\
=A_{k}\left[\begin{array}{l}
\left.\cos \left(2 \pi k \frac{x}{h}\right) \cos \left(2 \pi k \frac{\tau}{T}\right)-\right] \\
\left.-\sin \left(2 \pi k \frac{x}{h}\right) \sin \left(2 \pi k \frac{\tau}{T}\right)\right],
\end{array}\right.
\end{gathered}
$$

where $T$ is the period of oscillations in the main concentration wave, [s]. $A_{k}$ is the amplitude of the $k$-th harmonic of the concentration oscillations, $\left[\mathrm{m}^{3} / \mathrm{m}^{3}\right]$.

We construct the finite cosine integral transform into the coordinate, taking into account that the lengths of the concentration waves are multiples of the thickness of the adsorbent layer:

$$
\begin{aligned}
& \overline{C g}_{m}(\tau)=\int_{0}^{h} C g_{k}(x, \tau) \cos \left(\pi m \frac{x}{h}\right) d x= \\
& +A_{k} \cos \left(2 \pi k \frac{\tau}{T}\right) \int_{0}^{h} \cos \left(2 \pi k \frac{x}{h}\right) \cos \left(\pi m \frac{x}{h}\right) d x- \\
& -A_{k} \sin \left(2 \pi k \frac{\tau}{T}\right) \int_{0}^{h} \cos \left(2 \pi k \frac{x}{h}\right) \sin \left(\pi m \frac{x}{h}\right) d x .
\end{aligned}
$$
rule:

To find these integrals we use the frequency selection

$$
\begin{aligned}
& \int_{0}^{h} \cos \left(2 \pi k \frac{x}{h}\right) \cos \left(\pi m \frac{x}{h}\right) d x=\left\{\begin{array}{l}
2 m=k \Rightarrow \frac{h}{2} \\
2 m \neq k \Rightarrow 0
\end{array}\right\} \\
& \int_{0}^{h} \cos \left(2 \pi k \frac{x}{h}\right) \sin \left(2 \pi m \frac{x}{h}\right) d x=0
\end{aligned}
$$

With this in mind:

$$
\overline{C g}_{k}(\tau)=A_{k} \cos \left(2 \pi k \frac{\tau}{T}\right) \frac{h}{2} .
$$

Next, convert this expression to the form whith the differentiation operator with respect to time:

$$
\overline{C g}_{k}(s)=\frac{A_{k} h}{2} \frac{s}{\left(s^{2}+\left(\frac{2 \pi k}{T}\right)^{2}\right)} .
$$

Substituting this expression into the equation (21), after elementary transformations, we obtain the expression, easy to go back to its original:

$$
\bar{C}_{k}(s)=\frac{D_{E} \frac{\beta F}{K_{G}} \frac{A h}{2} s}{\left(s+\frac{\beta F}{K_{G}}+\frac{(\pi k)^{2} D_{E}}{h^{2} K_{G}}\right)\left(s^{2}+\left(\frac{2 \pi k}{T}\right)^{2}\right)} .
$$

Let transform it by the original image. The resulting expression is the sum of two components.

The first summand is an inverse exponential function by time. The steady state value of this function becomes equal to zero. The second summand of this original is the sum of sine and cosine.

For simplicity, we introduce the following notation:

$$
\begin{gathered}
B a_{k}=\left(\frac{D_{E} \cdot \beta F \cdot A_{k} h}{2 K_{G}}\right) \\
B c_{k}=\frac{\left(\frac{\beta F}{K_{G}}+\frac{(\pi k)^{2} D_{E}}{h^{2} K_{G}}\right)}{\left(\left(\frac{2 \pi k}{T}\right)^{2}+\left[\frac{\beta F}{K_{G}}+\frac{(\pi k)^{2} D_{E}}{h^{2} K_{G}}\right]^{2}\right)} \\
B s_{k}=\frac{\left(\frac{2 \pi k}{T}\right)^{2}}{\left(\left(\frac{2 \pi k}{T}\right)^{2}+\left[\frac{\beta F}{K_{G}}+\frac{(\pi k)^{2} D_{E}}{h^{2} K_{G}}\right]^{2}\right)}
\end{gathered}
$$

With consideration of this, original is:

$$
\bar{C}_{k}(\tau)=B a_{k}\left\{B c_{k} \cos \left(2 \pi k \frac{\tau}{T}\right)+B s_{k} \sin \left(2 \pi k \frac{\tau}{T}\right)\right\}
$$

Hence, we find a simple solution to equation of diffusion when its eigenwave passing through the adsorbent bed: 


$$
C_{k}(\tau, x)=\frac{2 B a_{k}}{h} \sqrt{B c_{k}^{2}+B s_{k}^{2}} \cos \left(2 \pi k\left(\frac{x}{h}+\frac{\tau}{T}\right)-\varphi_{k}\right)
$$

where

$$
\varphi_{k}=\operatorname{arctg}\left(\frac{B s_{k}}{B c_{k}}\right) .
$$

The physical sense of this formula is obvious. The oscillation amplitude of component concentration in a stationary frame is proportional to the amplitude of its oscillation in a carrier gas (at the entrance of adsorbent bed) multiplied by a coefficient that depending of carrier gas velocity and adsorbent properties.

Phase of the concentration oscillations in a stationary frame lags behind the oscillation phase in a carrier gas at the entrance of adsorbent bed.

In other words, at same speed of a carrier gas, velocity of concentration wave in adsorbent bed is less than velocity of the concentration wave out of adsorbent bed. Moreover, this speed difference affected by many factors, which including the Henry's law constant for gas adsorption. Is easy to verify, that the greater value of Henry constant the greater value of $B_{s k}$ and therefore more phase shift, and is less the speed of a concentration wave in the adsorbent bed.

Material balance of a component in elementary volume of carrier gas, moving inside adsorbed layer, can be written in the form of first order differential equation (2). The physical meaning of this equation is that the change in concentration of gas, moving in the pores, occurs only through mass exchange with the gas in a stationary frame.

We search for the solutions of this equation for the $k$ th iegenwave of adsorptive layer:

$$
C g_{k}(x, \tau)=A_{k} \cos \left[2 \pi k\left(\frac{x}{h}+\frac{\tau}{T}\right)\right] .
$$

The component from carrier gas can pass only into stationary frame; and vice versa, the component from stationary frame can move only to carrier gas. It follows that, if the concentration of component decreases in a carrier gas, it stationary frame concentration can only increase, and vice versa, if component concentration in a stationary frame decreases, it should increase in a carrier gas.

To satisfy this condition, represent concentration waves in a stationary frame as the function of sine:

$$
C_{k}(x, \tau)=A c_{k} \cdot \sin \left[2 \pi k\left(\frac{x}{h}+\frac{\tau}{T}\right)\right] .
$$

For functions of selected type, the equation of material balance (2) takes the form:

$$
\begin{aligned}
& \frac{\beta F}{G} A c_{k} \sin \left[2 \pi k\left(\frac{x}{h}+\frac{\tau}{T}\right)\right]- \\
& -\frac{\beta F}{G} A_{k} \cos \left[2 \pi k\left(\frac{x}{h}+\frac{\tau}{T}\right)\right]= \\
& =-\frac{2 \pi k}{h} A_{k} \sin \left[2 \pi k\left(\frac{x}{h}+\frac{\tau}{T}\right)\right] .
\end{aligned}
$$

By grouping the similar terms, and using the formula of difference identities for sine, we transform the last expression into a form convenient for analysis:

$$
\begin{aligned}
& A_{k} \sin \left[2 \pi k\left(\frac{x}{h}+\frac{\tau}{T}\right)-\psi_{k}\right]= \\
& =\frac{\frac{\beta F}{G}}{\sqrt{\left(\frac{2 \pi k}{h}\right)^{2}+\left(\frac{\beta F}{G}\right)^{2}}} \times \\
& \times A c_{k} \sin \left[2 \pi k\left(\frac{x}{h}+\frac{\tau}{T}\right)\right] .
\end{aligned}
$$

The expression above can be interpreted as a spatial lag between the concentration wave in carrier gas and the concentration wave in stationary frame.

The tangent of the phase angle between the component concentrations in a stationary frame and in a carrier gas is equal to:

$$
\omega_{k}=\operatorname{arctg}\left\{\frac{\beta F h}{2 \pi k G}\right\} .
$$

In steady state motion of a concentration wave, between carrier gas and adsorbent takes place multiple exchanges of component. As a result, the amplitudes of component mass oscillation in the carrier gas and in the adsorbent are identical. It follows that the amplitude of eigenoscillations of the component concentration at the outlet from adsorbent bed will be equal to half of oscillation amplitude at the entrance to this adsorbent bed.

In view of this, we obtain a comparatively simple solution to the concentration eigenwaves, at the outlet of adsorptive layer:

$$
C g_{k}(x, \tau)=\frac{A_{k}}{2} \cos \left[2 \pi k\left(\frac{x}{h}+\frac{\tau}{T}\right)-\varphi_{k}-\omega_{k}\right] .
$$

The physical sense of this formula is obvious: for eigenwaves propagating through the adsorbent bed, its frequency remains the same, and the phase of the wave delayed in time by an angle $\varphi_{k}$, and lags in space on the angle $\psi_{k}$. Moreover, phase angles are different for different concentration wave.

Essentially important for the considered mathematical model is that the system of eigenfunctions is complete. This means that any periodic sequence of arbitrary shape pulses can be with any desired degree of accuracy expanded in a finite series of these eigenfunctions. This position proved in mathematical analysis.

Therefore, any concentration signal entering into the adsorption column can be decomposed into the finite series of eigenfrequencies of this column. Further, having separately passed through the absorption column, we can combine back this eigenmodes into output concentration signal at the column outlet.

Thus, having the analytical solution for the set of 
eigenwaves in adsorption column, we can relatively easy to get a solution for any periodic sequence of concentration pulses.

We take as an example of these solutions the calculation of nitrogen pulse passage through the adsorption column.

Helium selected as a carrier gas. The pressure in the adsorption column is taken equal to 1,0 bar. Henry constant for adsorption of nitrogen is taken to be $1,0 \mathrm{~m}^{3} /\left(\mathrm{m}^{3} \cdot \mathrm{bar}\right)$, the temperature of adsorption column is $100^{\circ} \mathrm{C}$.

The formulas for definition of mass transfer coefficient are taken from [14]. The length of the adsorption column taken equal to $1,8 \mathrm{~m}$, velocity of the carrier gas in the column is taken equal to $0,18 \mathrm{~m} / \mathrm{min}$. The trapezoidal shape is given by input concentration signal.

First, decompose trapezoidal pulse of the nitrogen partial pressure in a Fourier series. To determine the coefficients of this expansion we use well-known formulas from the mathematical analysis:

$$
\begin{gathered}
a_{k}=\int_{0}^{h} f(x) \sin \left(2 \pi k \frac{x}{h}\right) d x ; \\
b_{k}=\int_{0}^{h} f(x) \cos \left(2 \pi k \frac{x}{h}\right) d x ;
\end{gathered}
$$

where $f(x)$ is a function expanded in Fourier series.

So having a sum of sines and cosines representation of an input concentration signal, we can easily predict the steady state output concentration signal. To do this, we are using equations $(32,33)$ and $(38,39)$ to find the Fourier series for the nitrogen concentration in the stationary frame, and in the carrier gas, leaving the adsorption column.

In this example, calculation made for the first hundred members of the Fourier series. This allows eliminating the termination effects of Fourier series.

Figure 5 shows the calculated curves for the nitrogen concentration at the entrance into the adsorption column 1 , in the outlet from the adsorption column 2 , and in the stationary frame (adsorbent) 3. The forms of corresponded graphs qualitatively are similar to chromatogram in gaschromatographic analysis.

As expected, during passage the concentration pulse through the adsorption column, shifted phases of individual harmonics of the concentration signal. This leads to broadening of the concentration signal in time and space.

Wave approach to investigations of cyclic adsorption and desorption processes is based on the concept of eigenwave in the adsorbed layer. Therefore, this method of calculation is necessary to determine the main eigenfrequency of the adsorptive layer.

From the definition of concentration eigenwaves follows that period of the main eigenwave is equal to retention time for the peak, corresponding to this component in the chromatogram.

In practical calculations, we may to find the period of

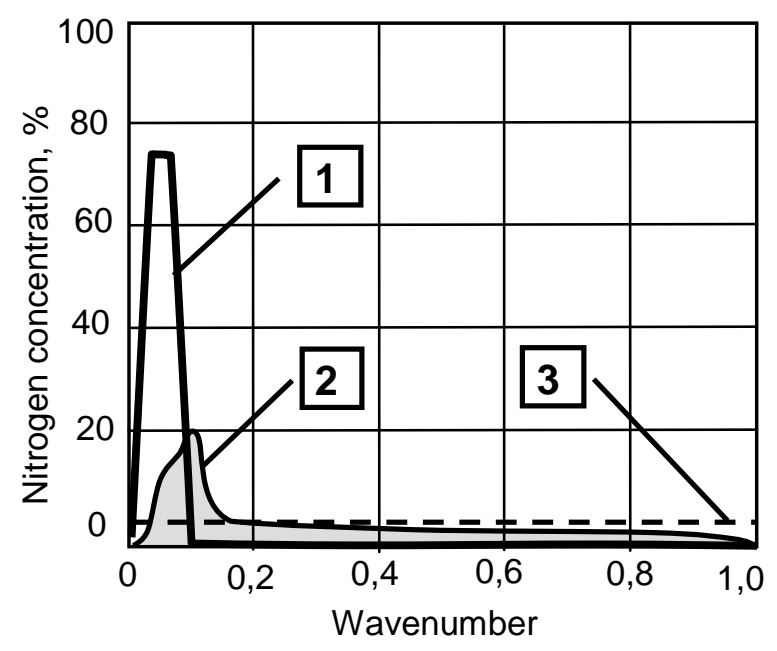

Figure 5 - The calculated graphics of concentration pulse passage in the adsorbed layer.

$\mathbf{1}$ - the form of concentration pulse at the inlet of the adsorption column;

2 - the shape of the concentration pulse in the output from the adsorption column;

3 - the form of the concentration pulse in the stationary frame.

main eigenwave by successive approximations.

Predetermined velocity of carrier gas and length of the adsorption column, it is easy to determine the time of the carrier gas passage across the adsorption column. This is a first approximation of the retention time of the component in the chromatographic column.

Then, using formulas (33) and (38), we find the phase shifts of the main concentration wave.

During the movement of the carrier gas in the chromatographic column, component move forward by a distance is equal to:

$$
h_{1}=h \frac{2 \pi-\omega_{1}-\varphi_{1}}{2 \pi} .
$$

where $h$ is the length of chromatographic column.

From this, it is easy to give a further refine speed of concentration pulse promotion in the chromatography column, and specify the period of its eigenwave in the chromatography column.

Repeating this procedure several times, we can determine velocity of concentration pulses of all components in the analysed gas mixture with acceptable accuracy.

Because the phase shift of concentration waves for each component not only depends on the value of adsorption, but also on the diffusion and the kinetic coefficients of mass transfer, the concentration waves move with different speeds. On this effect is based chromatographic separation of gas mixtures. 


\section{Results and Discussion}

\subsection{Analysis of the mathematical Model of Gas Chromatography}

As is done in the analytical gas chromatography, as a starting point we will accept nonsorbent component concentration wave, having the same period and initial phase of oscillations that the test component.

The mathematical model assumed that the carrier gas, as well as unretained component does not interact with the adsorbent. Therefore, the velocity of solute that does not sorb is equal to the velocity of the carrier gas.

The length of the concentration wave of unretained component may found as the product of the velocity of the carrier gas and the period of concentration wave for component does not sorb.

The height equivalent to a theoretical plate and, consequently, efficiency of chromatography column depends upon the velocity of carrier gas. The nature of this relationship is that it has an optimum velocity of carrier gas at which obtained minimum height equivalent to a theoretical plate or minimal broadening of concentration peaks.

The height equivalent to a theoretical plate for packed column, and carrier gas velocity connected to each other by the empirical van Deemter equation having the form [15]:

$$
h_{T}=A_{D}+\frac{B}{V}+C V,
$$

where $A_{D}, B$ and $C$ are constants; $V$ velocity of a carrier gas.

Because optimal values of carrier gas velocity is important for chromatography, literature gives various hypotheses about the physical meaning of constants $A_{D}, B$ and $C$, as well as recommendations to determine their value.

A minimum height equivalent to a theoretical plate obtained by the van Deemter equation, explained by the fact that this equation is the sum of a decreasing function hyperbole and increasing straight line.

Figure 6 shows graphs of phase shift of concentration eigenwave in the stationary frame $\left(\varphi_{1}\right)$, in the carrier gas, exiting chromatography column $\left(\omega_{1}\right)$, and the total phase shift angle $\left(\varphi_{1}+\omega_{1}\right)$ as a functions of the velocity of carrier gas.

It is clear that graph of the total phase shift for concentration wave is similar to function, which is the sum of hyperbole and a straight line.

Expression for the eigenwaves phase shift in stationary frame, after simplification, assumes the form:

$$
\varphi_{k}=\arctan \left(\frac{\left(\frac{2 \pi k}{T}\right)^{2}}{\left(\frac{\beta F}{K_{\Gamma}}+\frac{(\pi k)^{2} D_{\ni}}{h^{2} K_{\Gamma}}\right)}\right) .
$$

Considering that the kinetic mass transfer coefficient $\beta$ for laminar flow will be independent of the speed of carrier gas, denominator in this expression is a constant. The numerator only variable is a period of the main eigenmode $T$, which is inversely proportional to the velocity of the carrier gas.

Therefore, the phase shift angle of a concentration wave in the stationary frame is the arctangent function of square of carrier gas velocity:

$$
\varphi \approx \arctan \left(\text { const } \cdot V^{2}\right) .
$$

The spatial phase shift at the output of a chromatographic column is determined by the expression:

$$
\omega \approx \arctan \left(\frac{\text { const }}{V}\right) .
$$

This deduction is the spatial phase shift is decreasing function against velocity of carrier gas, like a hyperbola.

The implication of this analysis is that the phase shifts in space and in time versus to the speed of carrier gas is a decreasing and increasing functions that have a minimum.

As shown in Figure 6 (gray area), for small values of the argument, resulting function is well approximated by van Deemter equation, which is the sum of hyperbole and a straight line.

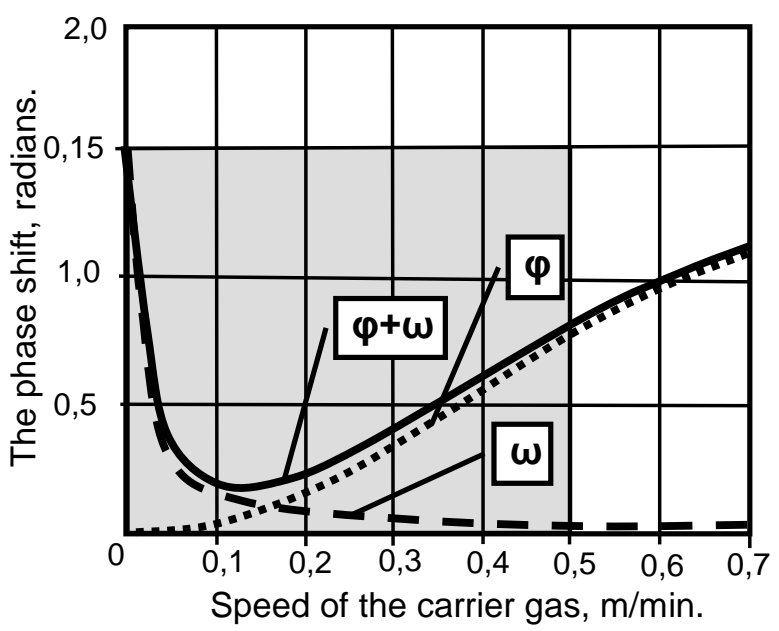

Figure 6 - The graphs of phase angle shift of concentration eigenwave as a function of the velocity of carrier gas.

$\boldsymbol{\varphi}$ - in a stationary frame;

$\boldsymbol{\omega}$ - in a carrier gas, filling the adsorbent bed;

$(\boldsymbol{\varphi}+\boldsymbol{\omega})$ - total phase shift.

Sometimes the van Deemter equation needs to improvement. For example, Giddings and Robinson [16] offered such modification of van Deemter equation:

$$
h_{T}=\frac{1}{1 / A_{D}+1 / C V}+\frac{B}{V}+C V .
$$


Another, more recent equation, the Knox equation [17], is applicable to various types of liquid chromatography:

$$
h_{T}=A_{D} V^{1 / 3}+\frac{B}{V}+C V .
$$

In these equations, into the classical van Deemter equation inserted an additional function, which is a convex in shape. This is necessary for a more accurate approximation of the dependence shown in Figure 6.

Summary phase angle $\left(\varphi_{\mathrm{i}}+\omega_{\mathrm{i}}\right)$ for each eigenmode of concentration signal finally defines a shape of concentration pulse exiting chromatography column. The smaller is the phase-shift angle between individual eigenmodes, the less be blurred the peaks on gas chromatogram, and therefore is less height equivalent to a theoretical plate.

Thus, the proposed mathematical model gives results that in good agreement with totality of experience in analytical gas chromatography.

There are parallels between the movement of concentration waves and the different nature wave's propagation, such as a light.

Movement of concentration waves in the adsorbent similar to the motion of the light waves in a transparent medium.

Light waves are slowed down when it passes through a transparent medium. This effect depends upon a nature of this medium. Quite similarly, a slow down of concentration waves depends on a nature of adsorbent.

Slowing down the light waves also depends of its frequency. On this property is based the spectral analysis. Due to different velocities of the light waves in a transparent medium, narrow light beam, in which mixed radiation from different atoms, decomposed in a spectrum.

Quite similarly, by different speed of the concentration waves of various substances, a short pulse of gas mixture passing through a chromatographic column stretching in a gas chromatogram.

From this point of view, it is quite natural similarity between optical spectrum of gas mixtures and view of a chromatogram, obtained by gas chromatography.

Similar to refraction of the light waves we could talk about refraction of concentration waves in a chromatography column.

Therefore, the wave approach to the consideration of periodic adsorption processes is not only a new method of calculation, but it is a same kind of a new paradigm in the adsorption technique.

\section{Conclusion}

The mathematical model of wave adsorption produces reasonable results that well agreed with empirical data to have accumulated in analytical gas chromatography.

Wave approach to the analysis of periodic adsorption processes enables to better understanding process of analytical gas chromatography.

The mathematical model of wave absorption can improve methods of calculating the sorption dynamic for a broad class of batch action adsorption apparatus.

\section{References}

1. Scott, R. P. W. (1998) Introduction to Analytical Gas Chromatography, 2-nd ed., Revised and Expanded. Chromatographic Science Series, Volume 76 (Georgetown University). Marcel Dekker: New York, 397 pp. DOI: https://doi.org/10.1021/ja9856021

2. Jennings, W. G.; Mittlefehldt, E.; Stremple, P. (1997) Analytical Gas Chromatography, 2-nd ed. Academic Press: San Diego, 389 pp. ISBN 0-12-384357-X DOI: https://doi.org/10.1021/ja975669t

3. McNair, H. M.; Miller, J. M. (1997) Basic Gas Chromatography; Wiley.

DOI: https://doi.org/10.1002/9780470480106

4. Grob R. L. (1995) Modern Practice of Gas Chromatography; 3rd ed.; Wiley. DOI: https://doi.org/10.1002/0471651141.ch2

5. Baugh, P. E. (1994) Gas Chromatography: A Practical Approach. The Practical Approach Series. Oxford University Press, Cary, NC, 426 pp. DOI: https://doi.org/10.1006/mchj.1994.1085

6. Scott, R. P. W. (1995) Techniques and Practices of Chromatography; 2nd ed.; Marcel Dekker.

7. Rood, D. (1995) A practical guide to care, maintainance and troubleshooting of capillary gas chromatographic systems, 2nd edition, Hüthig Verlag, Heidelberg. 323 pp. DOI: https://doi.org/10.1002/food.19960400221

8. Harris W. E., Habgood H. W. (1967) Programmed Temperature Gas Chromatography, John Wiley, New York.

9. Modern Practice of Gas Chromatography, Fourth Edition. (2004) Edited by Robert L. Grob and Eugene F. Barry ISBN 0-471-22983-0 John Wiley \& Sons, Inc. DOI: https://doi.org/10.1002/0471651141

10. Ruthven, D. M. (1984) Principles of Adsorption and Adsorption Processes. John Wiley \& Sons, New York.

11. Ruthven, D. M., Lee, L.-K., Yucel, H. (1980) Kinetics of non-isothermal sorption in molecular sieve crystals. AIChE J., 26, 16-23.

DOI: https://doi.org/10.1002/aic.690260104

12. Ruthven, D. M.; Farooq, S.; Knaebel, K. S. (1994) Pressure Swing Adsorption. VCH Publishers Inc. New York. 189 p.

13. Mikusiński J. (1956) Operational calculus. Publishing House of Foreign Literature, Moscow, 366 p. (in Russian). 
14. Aerov M. E., Todes O. M. (1968) Hydraulic and thermal basics of devices with fixed and fluidized granular layer. Chemistry, Leningrad, 512 p. (in Russian)

15. Giddings J. C. (1965) Dynamics of Chromatography, Principles and Theory. Marcel Dekker, New York. DOI: https://doi.org/10.1002/ardp.19662990719

16. Giddings J. C., Robinson R. A. (1962) Failure of the Eddy Diffusion Concept of Gas Chromatography. Analytical Chemistry. 34(8), 885-890. DOI: https://doi.org/10.1021/ac60188a005
17. Bristow P., Knox J. (1977) Standardization of test conditions for high performance liquid chromatography columns. Chromatographia, 10(6), 279-289. DOI: https://doi.org/10.1007/bf02263001

18. Kravchenko M. B. Wave adsorption. Saarbruecken, Lap. Lambert Academic Publishing, 2014, 168 p. (in Russian).

Received 11 October 2017 Approved 08 December 2017 Available in Internet 23 December 2017 